\section{Fibre does not protect against colon cancer}

Scott Gottlieb, New York

The largest study ever to examine the role of high fibre diets in protecting against colon cancer has found no benefit from eating fruits, vegetables, cereals, and other high fibre food products when it comes to preventing the disease (New England Journal of Medicine 1999;340:169-76).

The study, led by a team of researchers from Harvard University and Brigham and Women's Hospital in Boston, tracked the eating habits of 88757 female nurses aged 34 to 59 over 16 years. The study found that women who ate high fibre diets were no less likely to develop polyps, which can be precursors to cancer, or colorectal cancer than were women who ate little or no fibre.

The rarity of colorectal cancer in Africa had led Denis Burkitt to conclude more than a decade ago that the comparatively high intake of fibre by African populations compared with their Western counterparts conferred a protective benefit from developing colorectal cancer.

It was then postulated that dietary fibre prevented colorectal cancer by diluting or absorbing faecal carcinogens, reducing colonic transit time, altering bile acid metabolism, reducing colonic $\mathrm{pH}$, or increasing the production of short chain fatty acids.

Despite the intuitive appeal of these theories, epidemiological studies of a possible link between dietary fibre and colorectal cancer until now had been inconclusive. The present research was based on the nurses' health study, which since 1976 has been chronicling the health and habits of 121700 nurses who were aged 30 to 55 when the study began.

For this study, Charles Fuchs and his colleagues divided the women into five groups based on their median intake of fibre in 1980. They then studied only those women who maintained a consistently high fibre intake for the next six years, and tracked them until 1996. At the end of the period, they found that the percentage of women who had developed colorectal cancer was no different among the five groups.

Fuchs, an oncologist at Brigham and Women's Hospital and lead author of the study, cautioned that his team was unable to confirm whether fibre confers protective effects for other types of cancer.
"That is not to say that fibre is not a good thing. It still is helpful, but not for colon cancer," Fuchs said.

Many scientists believe that the response to dietary fibre may be different in women and men. Fuch's study group included only women. Arthur Schatzkin, senior investigator in the nutritional epidemiology branch of the National Cancer Institute, said that although the design of the present study was strong it was still possible that a link between fibre intake and colorectal cancer existed, but the epidemiological tools used in the study may have been unable to detect it.

He said definitive proof will be available after scientists complete ongoing controlled clinical trials comparing the rates of cancer in patients who eat fibre rich diets against those who do not.

\title{
College plans help for children in war zones
}

Kamran Abbasi, BMJ

A register of paediatricians willing to work as volunteers in war zones could improve the health of children in such areas, said speakers at the international task force conference of the Royal College of Paediatrics and Child Health in London last week.

The register would, however, be only a first step, and a more cohesive strategy needs to be developed. An effective plan would have to involve the medical colleges, non-governmental organisations, donors, and the armed forces.

Professor David Baum, president of the Royal College of Paediatrics and Child Health, emphasised the importance of a comprehensive but cautious approach: "The responsibilities of the college are to do with the delivery of the best health care for children in this country, and we have taken this work [in war zones] on following demand from the membership. While the work is important, we should not be consumed by this."

Over the past decade, two million children have been killed in areas of conflict, four to five million have been seriously injured, and 12 million have been made homeless (BMJ 1998;316:1549-50).

A register of paediatricians offering to provide care internationally was established last year after the college sent a questionnaire to all members. Out of 4200 paediatricians, 68 were willing to be placed on the register and had experience of international aid work, 133 were willing to go on the register but had little or no experience, and 26 were unavailable for work but willing to act as mentors for those sent on international service. The names of volunteers are simultaneously held by the International Health Exchange, an organisation involved in recruiting for international aid agencies.

Conference delegates-paediatricians, aid workers, and Princess Anne, the patron of the college-acknowledged that the register was a valuable contribution to child health but its future success would depend on many factors such as regular updating, maintaining a high profile, and the sustainability of projects. Also important would be the ability of doctors to secure time off work, to receive accreditation

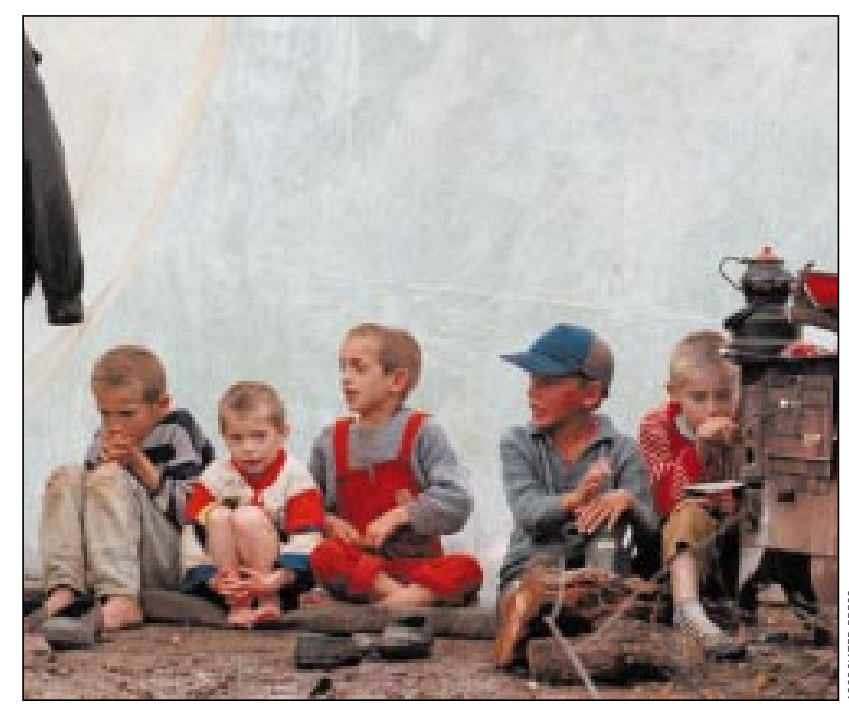

Volunteer paediatricians could help protect children in war zones

for higher specialist training while volunteering, to be safe while working in areas of conflict, and to be accountable while working internationally. The college believes that the specialist registrar grade offers the ideal time and the necessary flexibility for doctors to volunteer for the register.

Jane Schaller, professor of paediatrics at Tufts University in the United States and president elect of the International Paediatric Association, applauded the college for taking a lead in promoting children's health internationally: "The time when we said that these aren't our children and they're not our responsibility has passed. What happens to them affects our future and our world."

The International Task Force on Children Affected by War and Absolute Poverty was formed in 1997 by the Royal College of Paediatrics and Child Health. It aims to contribute to the health of children in war zones and in areas of natural disaster, in emergencies and their aftermath, as well as to provide support when children are internally displaced or become refugees. 